American Journal of Economics and Business Administration 3 (2): 312-320, 2011

ISSN 1945-5488

(C) 2011 Science Publications

\title{
Power Outage, Business Continuity and Businesses' Choices of Power Outage Mitigation Measures
}

\author{
${ }^{1}$ Ali Asgary and ${ }^{1,2}$ Yeganeh Mousavi-Jahromi \\ ${ }^{1}$ Emergency Management Profram, School of Administrative Studies, York University, \\ Toronto, Ontario, M3J 1P3, Canada \\ ${ }^{2}$ Department of Economics, Payame Noor University, Tehran, Iran
}

\begin{abstract}
Problem statement: Power outage has been mentioned as one of the most experienced and perceived risks by various types of businesses and organizations. Thus, reducing the impacts of power outage has become a key agenda in business continuity planning. Back-up or stand-by generators are among the most well known measures taken by power consumers to tackle the power outage problem. Approach: A survey was conducted to understand various aspects of power outage and the impacts of power outrage on businesses. In addition a choice experiment method was used to derive businesses' preferences for different power outage mitigation measures that would have a range of prices, space requirements, air and noise pollution as well as mobility attributes using a sample of Canadian businesses located in the . Sample was drawn from businesses operating in the Greater Toronto Area (GTA) and surrounding communities in Ontario, Canada. Results: It was found that majority of businesses have experienced and unconvinced by power outage and consider it to be a major risk to their operations. Production loss, data loss, damage to equipment and loss of lighting are the most significant sources for inconveniences caused by the power outages. It was found that a considerable number of businesses have not taken appropriate measures to mitigate this risk. Estimations from the responses revealed that sample businesses had a positive willingness to pay for power outage reduction and that businesses prefer power outage mitigation measures that are least costly, have low levels of air and noise pollution and occupy smaller spaces respectively. Conclusion: An uninterrupted power supply is an important element of business continuity in today's business world. Although many businesses are not fully prepared against power outages, they are willing to pay for low cost and low pollution power outage mitigation measures.
\end{abstract}

Key words: Power outage, choice experiment, business continuity, Power Outage Mitigation Measures (POMM), cyber, thunderstorms, Greater Toronto Area (GTA), Uninterruptible Power Supply (UPS)

\section{INTRODUCTION}

Reducing disruptions caused by natural, technological, or human made hazards are among the main goals of business continuity planning. The risk of business interruption has increased in recent years as businesses become more and more dependent on information technology infrastructure and are more closely linked to external networks (Cerullo and Cerullo, 2004; Momani, 2010). In the past decade a series of disaster events occurred with significant impacts on businesses around the world and as a result more businesses are taking necessary measures to reduce these disruptions. The power outage in the Northeastern US and Canada on August 2003 was just an example of a major outage in modern industrial societies that had significant economic impacts. Power outage has been considered to be a key source for business disruptions at different levels. Recent studies show that majority of businesses have either experienced power outage on a regular basis or perceive power outage to be a major source for business disruptions. For example in a survey conducted in 2001 it was found that more than $70 \%$ of companies interviewed had been impacted by a power outage (KPMG, 2002). In a recent international survey it was revealed that more than $87 \%$ of the sample businesses had activated their business continuity plans due to a power outage (BC Management, 2009). Such power outages generate significant costs to businesses and

Corresponding Author: Ali Asgary, Emergency Management Profram, School of Administrative Studies, York University, Toronto, Ontario, M3J 1P3, Canada 
power consumers. LaCommare and Eto (2006) estimated that the annual cost for power interruptions to US electricity consumers is $\$ 79$ billion. Of this amount, the commercial sector accounts for more than 72\% (\$57 billion) of the total outage cost, the industrial sector represents nearly $26 \%$ of the total cost and the residential sector accounts for less than 2\%. Despite this, many businesses are not prepared for disruptions by preparing business continuity plans. For those businesses that do acknowledge having a plan, many of them have not addressed basic infrastructure such as alternative power sources (Paddon, 2004).

Considering all these situations, businesses have started looking for measures to mitigate the risk of power disruptions and minimize their negative impacts. Because of such demands, power and business continuity companies offer different types of power outage mitigation solutions. Businesses could benefit from the introduction of Power Outage Mitigation Measures (POMM) where power outage is judged to be a serious risk for business continuity. In this study POMM are measures that are taken to produce enough power in-house by means of various power generators and battery systems so that businesses can continue their functions or at least their mission critical functions until the networked power is restored. Implementation of these measures involves cost, requires space and generates air and noise pollution. The purpose of this study is to evaluate these benefits and to investigate how important various attributes are for businesses when choosing among different POMMs.

Business continuity, power outage and power outage mitigation measures: In addition to the day to day pressures of operating a business, companies are now faced with more extreme natural, technological and new varieties of human induced threats (terrorist acts, computer viruses, cyber crime and anti-globalization riots). With the introduction of business continuity planning and as a result of increasing awareness in regards to emergency preparedness, businesses have started realizing the importance of continuous power supply for smooth running of their functions. There are many factors that contribute to the continuity of businesses but constant supply of electricity is a lifeline for most businesses. For any business or organization, being prepared means ensuring a constant and uninterruptible source of power will remain up and running. Businesses must be able to withstand a loss of electricity for an extended period of time to ensure everything from continued operations to inventory controls.

Existing evidences show that a large percentage of power outages are caused by weather-related events including thunderstorms, ice storms, heavy winds and lightning strikes, as well as other natural disasters like floods, hurricanes, or tornadoes (Baltimore Gas and Electric Company, 2011). Animals contacting wires, auto accidents damaging poles or other equipment and other unknown factors can also cause power outages. Terrorist attack and sabotage have also been established as the potential causes of power failures. Power outages may vary by season and can last from minutes to hours, or even days depending on the severity of the event. The loss of electric power in Canada due to natural events such as the 1998 ice storm, technical or accidental causes such as the 2003 blackout and other hazardous events and system failures have become familiar to vast majority of the businesses in Ontario, Quebec and the Atlantic provinces. In the USA, the 2003 blackout was considered to be the largest event of its kind in North American history. This blackout crippled most of the east coast and Midwest and resulted in initial estimates of losses totaling $\$ 6$ billion (Hilsenrath, 2003). Whatever may be the cause, the consequences of power outage pose tremendous negative impacts on businesses and the economy in addition to social inconvenience for citizens. Studies show that after human error, power failures have been the second most common cause for business interruption in the USA (Disaster Recovery Journal, 2003).

Emerson network power, recently commissioned an online survey of 451 small business owners to determine whether they were equipped to deal with a power disruption. The results showed that only 39\% of small businesses had backup power systems (Emerson Network Power, 2008). This indicates that in the event of a power failure, the majority of small companies would find themselves unequipped. They would be unable to keep the lights, the computers and cash registers running or their employees working and therefore would be unable to facilitate continued operations The survey showed that $79 \%$ of the respondents had at least one power failure during 2007 while $29 \%$ (one in four) had three or more and that $42 \%$ of those companies had to close their business during the outage.

Power failure-related downtime affecting even a small portion of businesses could have a significant impact on the overall economy (Emerson Network Power, 2008). Businesses are also increasingly vulnerable to power interruptions to their supply chain (Webb et al., 2000), e.g., as a result of “just-in-time” inventory management and increasing reliance on information technology and networks (Zolkos, 1997).

Power outage problems and risks are intensifying in the business sectors, in part because computing and networking technologies are becoming more sophisticated. New high-density storage devices, blade servers and network processors use components so 
miniaturized that they falter and fail under power conditions that earlier equipments could have easily withstood. Information systems, unlike 20 years ago, are the very core of all business processes. If a mass storage device, a server, or critical network connections goes down, the business cannot function normally. In today's business world, the cost of downtime has increased considerably. So has the likelihood of power-induced failures. Therefore, uninterrupted power is critical for the smooth running of a business (Loeffler, 2008).

The actual costs of power interruptions to businesses are numerous and complex and include direct and indirect costs. Direct costs for commercial and industrial firms may include lost product, idle factor costs, shutdown costs, restart costs, spoilage, damage to raw materials and equipment, back-up costs and health and safety costs. Indirect costs may include the costs to downstream firms and final consumers (Eto et al., 2001). The impacts of power outage on businesses depend on magnitude, duration and frequency of the events, when they occur and the degree of advance notice. The 'magnitude' of an event is the extent to which it deviates from normal operation. Prior notification and estimation of downtime can substantially reduce equipment damage and cost. Large deviations often damage equipment and interrupt services, while small deviations may not even be noticed by consumers. 'Duration' is the length of the event. While even a short outage leads to a high direct cost, an outage of a week or month can exacerbate indirect costs. 'Frequency' is how often an outage occurs. Frequent outage can damage equipment. 'Timing' specifies when the event occurs: time of the day, day of the week and season of the year. Weekday daytime events are more likely to cause interruptions in the businesses. Advance notice allows power customers sufficient time to make adjustments that reduce the cost of an interruption. For industrial businesses, advance notice may allow controlled shutdown, preventing damage to equipment and raw material that might occur in an unexpected outage (Eto et al., 2001).

Reports of specific power system events tend to focus on large outages. However, estimates of costs associated with these events are not well documented and generally not useful for developing more aggregate estimates. For example, a 15 min power outage in Vancouver, British Columbia, shut down the Vancouver Stock Exchange for an entire day (Wintrob 1995). The outage occurred after trading hours and there seemed to be little cause for concern until the system was brought up the next morning. Data and the back-up file were both corrupted. The problem was not resolved in time to open the exchange that day. The lost revenue to the stock exchange was about 30,000
Canadian dollars, but lost commissions for member firms pushed losses into millions. Two outages in the summer of 1996 affected the western U.S. The August 10 outage affected fourteen western states and two Canadian provinces. Brown (1996) discusses the impact of the outages on semiconductor manufacturers. Most of the manufacturers reported some product damage and one reported equipment damage. Additionally outages can disrupt security systems, facilitate burglary losses and delay the response of police and fire services. Electricity interruptions also interfere with traffic signal lighting, which can cause roadway accidents and associated losses. Although business interruptions can be triggered by a range of events, electric power interruptions are responsible $70 \%$ of the time (Rodentis, 1999).

\section{METERIALS AND METHODS}

Data was collected through a questionnaire survey conducted in 2009. The survey instruments consisted of three parts. The first part was intended to find information about the businesses and their business continuity efforts. The second part included a number of questions about the businesses' power outage experiences and use of POMMs by them. The third part contained questions related to the businesses choices of power outage mitigation measures to elicit businesses' preferences for several bundles of attributes of POMMs using a contingent ranking choice experiment method.

Contingent ranking is a survey-based method that is used for modeling preferences for goods or services, where goods or services are described in terms of their attributes and levels. Survey respondents are usually presented with various alternative descriptions of a good or service, differentiated by their attributes and levels. Respondents are asked to rank or rate the various alternatives, or to choose their most preferred. By including price/cost as one of the attributes of the good or service, WTP can be indirectly ascertained from respondents' rankings, ratings or choices. Survey based attribute valuation approaches such as contingent ranking allow a more direct route to the valuation of the characteristics or attributes of a good or service and of marginal changes in these characteristics. Choice-based modeling such as contingent ranking uses random utility function for choice analysis, rank ordered logit as model specification and the maximum likelihood as the estimation procedure (Louviere et al., 2000).

A typical contingent ranking choice experiment design exercise consists of five steps (Louviere et al., 2000; Green and Srinivasan, 1978; 1990): (1) defining attributes, (2) assigning attribute levels, (3) creating scenarios, (4) determining choice sets and obtaining preference data and (5) estimating model parameters. In this study in order to define the attributes, first a list of 
Am. J. of Economics and Business Administration 3 (2): 312-320, 2011

Table 1: Attributes and levels

\begin{tabular}{ll}
\hline Attributes & Levels \\
\hline $\begin{array}{l}\text { Cost of power outage } \\
\begin{array}{l}\text { Mobilitity of the powere } \\
\text { mitigation measure }\end{array}\end{array}$ & 1000 \$, 10000 \$, 20000 \$, 40,000 \$ \\
$\begin{array}{l}\text { Size and space needed for power } \\
\text { outage mitigation measure }\end{array}$ & Fixed (1), Mobile (2) \\
$\begin{array}{l}\text { Pollution level (air and noise) } \\
\text { Soll (1), medium (2), large (3) }\end{array}$ & Low (1), medium (2), high (3) \\
\hline
\end{tabular}

potential attributes for power outage mitigation measures was developed using literature and face to face interviews with companies developing power outage mitigation measures. In order to keep the total number of attributes as low as possible and reduce the complexity of choices four attributes were chosen: cost of power outage mitigation measure, mobility of the power outage mitigation measure, size and space needed for power outage mitigation measure, pollution level (air and noise). The final list of attributes and levels are shown in Table 1.

The third step in the choice experiment involves creating choice scenarios. If the number of attributes and levels is small, all possible combinations could be used in the experiment. When the number of attributes and/or the number of levels increases the number of possible different profiles increases exponentially. Four attributes each with at least two levels provide a large combination of alternatives. Therefore, an orthogonal design technique was used to reduce the total number of choices to a practical number (Louviere, et al., 2000). This technique selects a subset of all possible factorial combinations, which will have proper representation of the full set (Aas et al., 2000). After using this technique and removing some of the unreal choices sixteen alternatives were derived and used in the survey. We presented each respondent with four alternative choices to rank. A sample choice scenario is shown in Fig. 1.

Several studies have examined the willingness to pay for improving power reliability and quality outage using contingent valuation and choice experiment methods for the households (Carlsson and Martinsson, 2007; 2008; Asher et al., 2008), but businesses' choices for power outage mitigation measures have not been studied as much. This study employs a choice experiment method to find out businesses' choices for power outage mitigation measures.

A sample of businesses in the Greater Toronto Area (GTA) and surrounding communities were selected from Canadian D\&B business database using a stratified sampling method. Questionnaires either were handed to the businesses directly or completed on site through face to face interviews. In total we received about 482 completed questionnaires in which there were 235 (54\%) small businesses samples (businesses with 50 or less employees), 165 (34.2\%) samples from the medium size businesses (businesses with 51-500

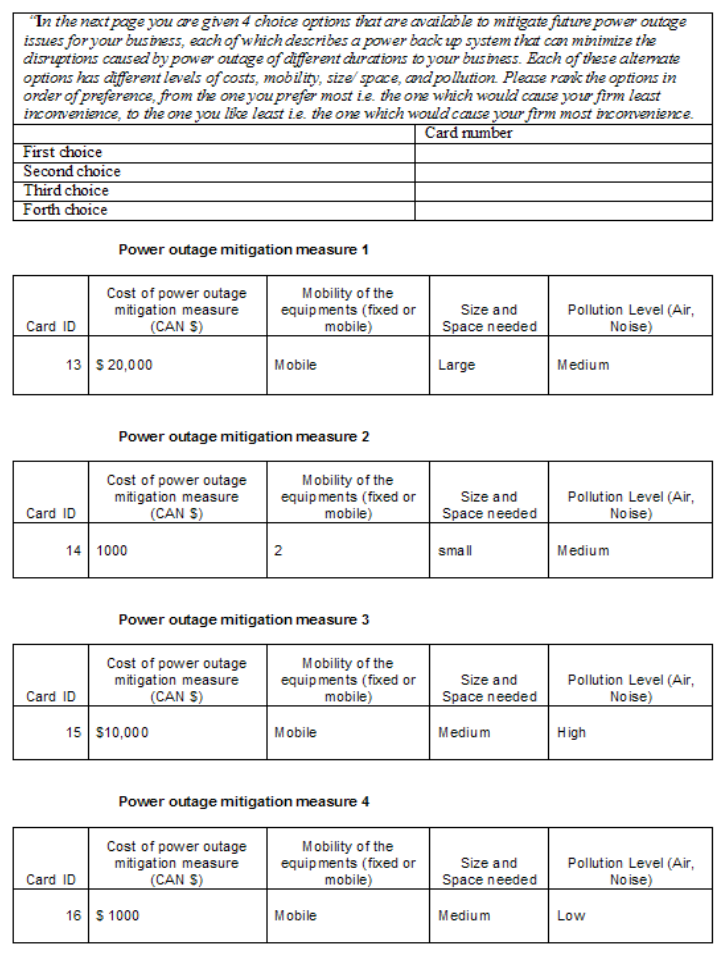

Fig. 1: Sample choice card

employees) and 25 (11.8\%) samples from the large businesses (businesses with more than 500 employees). The geographic scopes of the sample businesses' operations were as follows: local (29\%); regional (21\%); national (14.7\%); North America (12.4\%); and international (20.5\%). About $54 \%$ of the sample businesses own their locations and the rest operate in rented facilities and buildings. Our sample included businesses of various types but mainly from service sector (retail, wholesale, public administration, arts, entertainment and recreation, manufacturing, finance and insurance and professional services). A considerable number of businesses that completed the survey (61.5\%) were operating in facilities that are part of multisided businesses. A majority of the sample businesses had been established between 11-20 years ago, followed by $20.2 \%$ that were established more than 50 years ago.

Sales and marketing (63.5\%) followed by the administration (45.5\%), financial services (21.4\%) and manufacturing (19.9\%) are the most crucial functions in the sample businesses, research and development with (17.6 \%), logistics (18.3\%) and others (14.9\%) found to be less crucial functions among them.

\section{RESULTS}

Significance of power and power outage for businesses: Before presenting the results of businesses' 
preferences for power outage mitigation measures, it is important to present some of the general findings related to business continuity planning, hazards and risks, power usage and importance of power and electricity among the sample businesses. More than half of the sample businesses (51.1\%) indicated that they had a documented business continuity/emergency management plan. A majority of the sample businesses had prepared their plans in the past 10 years. The results (Fig. 2) show that loss of power, loss of people, loss of information technology, extreme weather, loss of telecommunications and employment safety are among the top hazards that businesses are concerned about or perceive to be a threat to their operations. The results also show that loss of power (57.3\%), loss of people (45.4), loss of information technology (43.6\%), employees' safety incidents (42.1\%), loss of telecommunication (38.6\%), loss of skills (35.3), fire (31.1\%), damage to corporate reputation (30.9\%), negative publicity (30.1\%) and supply disruption (27.4\%) have been among the top reported hazards that businesses have experienced in the past year.

As far as power usage is concerned, lighting (90.2\%), air conditioning (85.5\%), computertelecommunication (82.5\%), office equipments (79.9\%), security systems (72.2\%), ventilation (63.5\%) and refrigeration $(54.8 \%)$ are among the top electricity uses in the sample businesses. While small businesses might not be impacted by short term power outages, medium and large businesses could suffer huge losses even from a few minutes of power outages. Among the businesses that had experienced power outages in the past recent years, about half of them (50.7 \%) indicated that the total monetary costs of power outage were less than $\$ 10,000$. Others had experienced more losses. We asked our sample businesses about how disruptive various levels of power outages would be for their businesses. Results show that all types of power outages are disruptive for them, but the longer the power outages are, the more disruptive they will be. For example, while a $6 \mathrm{~h}$ power outage is extremely disruptive for only $26.3 \%$ of the sample businesses, a one week power outage is extremely disruptive for $81.5 \%$ of them (Fig. 3).

Similarly we asked about the disruptive impacts of power outages in different seasons. The results show that there isn't a huge gap between the disruptiveness of the power outage in different seasons of the year for businesses (Fig. 4). The winter season was mentioned as extremely disruptive by $55.2 \%$ of businesses and spring was mentioned as extremely disruptive by a comparable $48.8 \%$ of businesses.

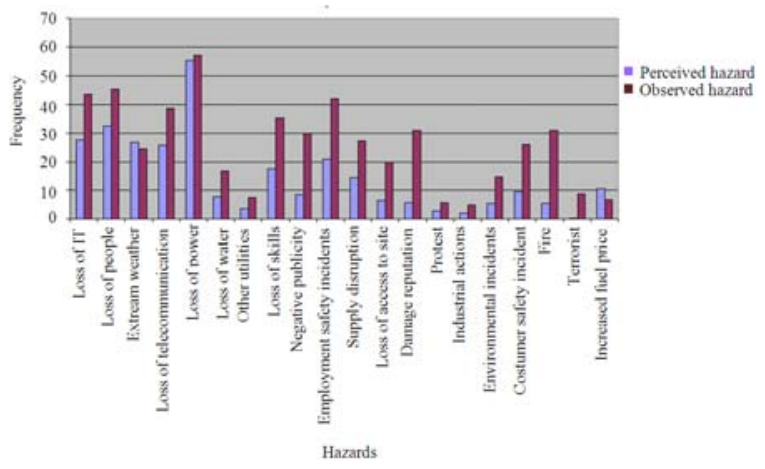

Fig. 2: Perceived and experienced hazards in the past year by sample businesses

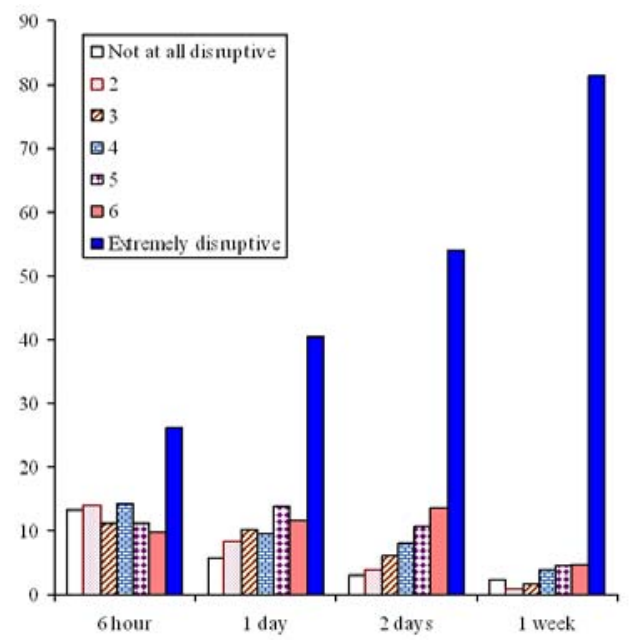

Fig. 3: Disruptive levels of power outages of various lengths for businesses

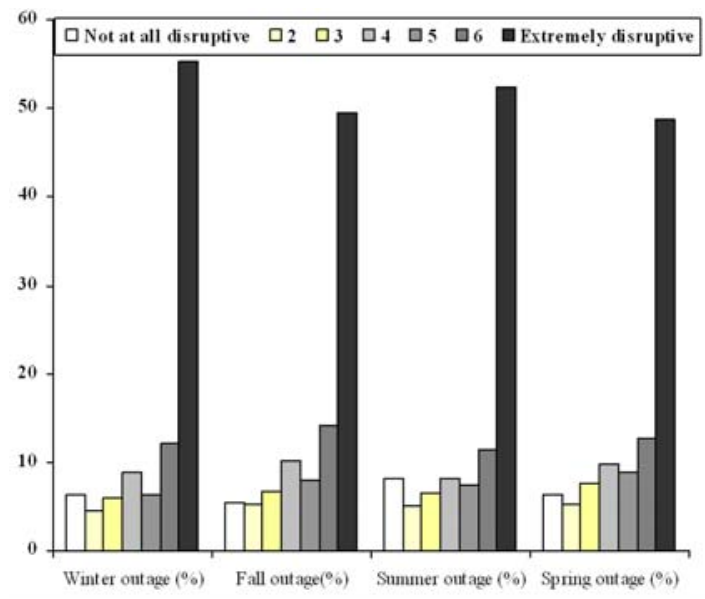

Fig. 4: Disruptiveness of power outage for businesses in different seasons 
When businesses were asked about the average cost of a 1 hour power disruption, about $50 \%$ of the businesses believed that it would cost them less than 5,000 dollars, $11.6 \%$ of them estimated that the hourly cost of the power disruption would be between $\$ 6,000-10,000$ and $7.3 \%$ have mentioned this to be between $\$ 11,000$ $\$ 25,000$ (Table 2). As expected considerable number of businesses do not know the exact costs of potential power outages because of the difficulties in calculating this (LaCommare and Eto, 2006).

While the majority of sample businesses have indicated that they would be very inconvenienced by a potential power outage, only $5 \%$ of the sample businesses are not inconvenienced by a potential power outage (Fig 5). These are businesses which are not heavily dependent upon power to run their main functions.

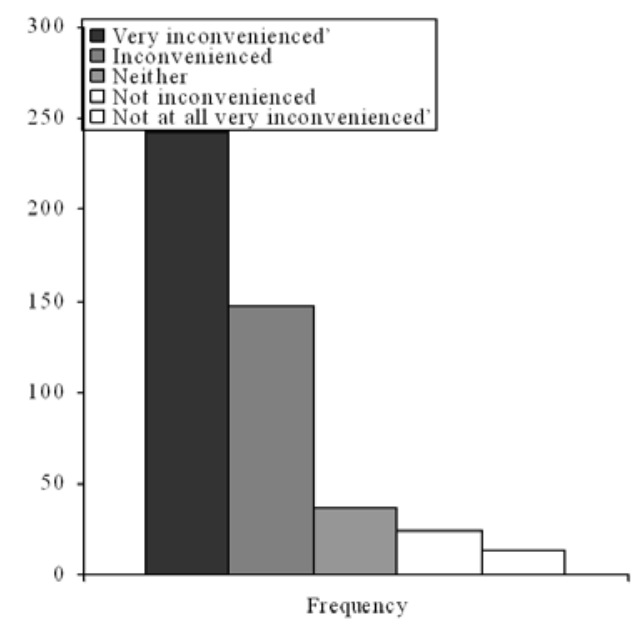

Fig. 5: Level of inconveniences caused by a power outage

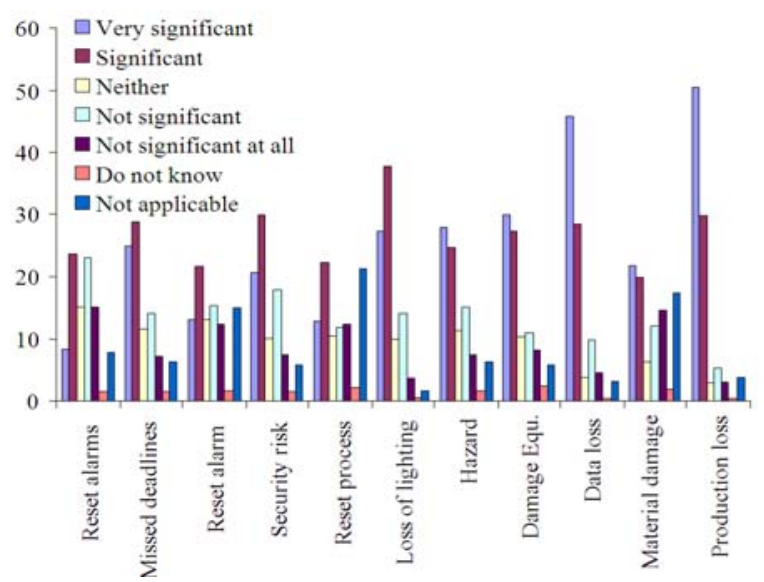

Fig. 6: Significant sources of inconveniences
When asked about the sources of the inconveniences, it was found that production loss (50.4\%), data loss (45.9\%) and damaged equipment $(29.9 \%)$ were the most significant sources for inconveniences caused by the power outages (Fig. 6).

Finally, we asked a question about the type of provisions that businesses have taken to minimize the impacts of power outages. The results are presented in Table 3. About $40 \%$ of the businesses interviewed have standby electrical generators. Almost half of the businesses have back up power sources for their computers. The majority of the businesses (52.5\%) have listed insurance as one of their measures. These findings clearly show that at least half of the businesses have not taken any mitigation measure to minimize the impacts of power outages.

Choice of power outage mitigation measures: As mentioned earlier we used a contingent ranking technique to find out businesses' preferences for various power outage mitigation measures.

As mentioned earlier we applied a multinomial logit regression to estimate the sample businesses' preferences for power outage mitigation measures. The results are presented in Table 4. For each parameter, the estimated coefficient, standard error and significance or p-value and marginal values are reported. According to the results, three attributes (cost, size/space and pollution (air and noise)) had significant impact on the businesses' choices with expected signs, but the mobility factor was not found

Table 2: Hourly cost of a major disruption caused by the power outage

\begin{tabular}{lcc}
\hline & Frequency & Percent \\
\hline Less than \$5,000 & 232 & 49.8 \\
$\$ 6,000-\$ 10,000$ & 54 & 11.6 \\
$\$ 11,000-25,00$ & 34 & 7.3 \\
$\$ 26,000-50,000$ & 9 & 1.9 \\
$\$ 51,000-100,000$ & 12 & 2.6 \\
$\$ 100,000-500,000$ & 8 & 1.7 \\
More than \$5 million & 6 & 1.3 \\
Do not know & 109 & 23.4 \\
Total & 466 & 100.0 \\
\hline
\end{tabular}

Table 3: Provisions to minimize the problems associated with a power outage

Provisions for power outage Percent

Standby electrical generator $\quad 40.0$

Insurance $\quad 52.5$

Emergency lighting $\quad 50.0$

Uninterruptible Power supply (backed by battery) 40.0

Computer back-up $\quad 50.6$

Agreement with third party providers $\quad 19.1$

Batteries $\quad 27.6$

Power gas light $\quad 8.9$

Candles, torches $\quad 17.0$

Wind power $\quad 0.6$

Sun energy $\quad 1.5$

Thermal energy $\quad 1.7$

\begin{tabular}{ll} 
Others & 1.7 \\
\hline
\end{tabular} 
Am. J. of Economics and Business Administration 3 (2): 312-320, 2011

Table 4: Logit regression results for contingent ranking

\begin{tabular}{lrllc}
\hline & & & & Marginal value \\
Variables & Estimate & Std. Error & Sig. & (Canadian dollar) \\
\hline Cost & -0.000028 & 0.000 & 0.000 & 1.00 \\
Mobility & -0.014000 & 0.098 & 0.884 & 500.00 \\
Size/Space & -0.271000 & 0.059 & 0.000 & 9678.57 \\
Pollution (air \& noise) & -0.44900 & 0.059 & 0.000 & 16035.71 \\
\hline \multicolumn{2}{l}{ Model fitting information Chi $^{2}=138.648$} & (Sig. 0.000); Goodness of \\
Fit : Pearson Chi ${ }^{2}=268.418$ (Sig. $\left.=0.000\right)$
\end{tabular}

to be statistically significant. In other words, the higher the costs of POMM are, the less likely that businesses choose them. Similarly, businesses prefer POMMs that require less space and have smaller amount of air and noise pollution.

Dividing the estimated coefficients by the cost attributed provides us with the relative marginal values (see last column of Table 4) or willingness to pay for each attribute.

\section{DISCUSSION}

Our study provides some insights into the power outage risk and business continuity and the business continuity provisions that are in place to reduce this risk.

While businesses face a range of risks caused by natural technological, or humans, power outage is among the most perceived and experienced risks by majority of them. Our findings reconfirm similar results attained in the surveys conducted in other parts of the world (KPMG, 2002; BC Management, 2009). We found that power outage is the most perceived and experienced hazard by considerable number of businesses.

As more and more businesses rely on information technology and interdependencies between critical infrastructure increases, power outages become a major source of inconvenience for them. Majority of businesses cannot tolerate long term power disruptions especially if they go beyond one day which is usually the case where major disaster events occur. Businesses should realize that many of them are not in the priority list of emergency power supply and therefore should prepare themselves for such situations.

Our analysis of the data provides support for the main purpose of the paper: to suggest that businesses are willing to pay for mitigating power outage, but in doing so they prefer mitigation measures that are less costly, generate less air and noise pollution and occupy smaller spaces. Mobility of power outage mitigation solutions does not seem to be an important decision factor for businesses. In particular, they prefer and willing to pay more for measures that produce less air and noise pollution. Considering that majority of our sample businesses are small and medium size business it seems very relevant. These findings could provide directions for companies that supply power outage mitigation measures or alternative services.

The costs of power outages and importance of business continuity under power disruptions has led businesses to invest in a wide variety of POMM to reduce their vulnerability to such events. Back-up or stand-by generators as well as energy-storage technologies, such as batteries and flywheels are among the most well known measures. (LaCommare and Eto, 2006). In business continuity planning particular attention has to be paid to power supply. A business continuity plan should cover the provision of back-up generators or interruptible power supplies to allow critical business processes to continue, or to be closed down "gracefully" when there is a power outage. This is particularly true of IT systems where data can be corrupted by intermittent power supply and even by the potential power surge or drop when the main power source fails and a back-up generator is switched in. The business continuity plan must document the existence of such back-up generators and Uninterruptible Power Supply (UPS) and the functions that they are able to support or manage. The plan should also detail the testing procedures and record when they were last tested (Savage, 2002).

\section{CONCLUSION}

Power outage is one of the most experienced and perceived hazards for businesses. Recent large disaster events have shown that power outages could disrupt businesses and create major economic losses. Business continuity requires businesses to invest in mitigation measures for hazards, including power outages. There are varieties of power outage mitigation measures that could be used by businesses to reduce the risk of power disruptions. Businesses' preferences for investing in the POMMs in part depend on the attributes of these measures. While investigating the importance of power for business continuity and impact of power outages on business functions in a sample of businesses in Canada, this study examined the relative importance of the attributes of different power outage mitigation measures. It was found that majority of businesses have experienced a power outage and consider it to be a major risk to their operations. Most businesses are severely affected and inconvenienced by power outage, especially when the duration exceeds more than two days. Production loss, data loss, damage to equipment and loss of lighting are the most significant sources for inconveniences caused by the power outages in businesses. It was found that a considerable number of 
businesses have not taken appropriate measures to mitigate this risk. The results of choice experiment method showed that cost, size/space and pollution level had significant impacts on businesses choices for the POMMs. Companies that are supplying power outage mitigation measures could use these findings to provide products that better meet the needs of businesses in this regard. In order to increase the demand for their power outage mitigation measures, they should focus on products that are less costly, have smaller amounts of air and noise pollution and require less space.

\section{ACKNOWLEDGEMENT}

This research was funded by the Social Sciences and Humanities Research Councils.

\section{REFERENCES}

Aas, O., W. Haider and L. Hunt, 2000. Angler responses to potential harvest regulations in a norwegian sport fishery: A conjoint-based choice modeling approach. North Am. J. Fisheries Manage., 20: 940-950. DOI: 10.1577/15488675(2000)020\&lt;0940:ARTPHR\&gt;2.0.CO;2

Baltimore Gas and Electric Company, 2011. What Causes Power Outages? Edison Electric Institute. http://www.bge.com/portal/site/bge/menuitem.fe9c 7e782b73e84606370f10d66166a0/

BC Management, 2009. International business continuity program management benchmarking report an executive summary. BC Management, Inc.

http://www.bcmanagement.com/uploads/3/7/5/2/37 52086/intl_program_mgmt_benchmarking_reportsummary.pdf

Carlsson, F. and P. Martinsson, 2007. Willingness to pay among Swedish households to avoid power outages: A random parameter Tobit model approach. Energy J., 28: 75-90.

Carlsson, F. and P. Martinsson, 2008. Does it matter when a power outage occurs? -- A choice experiment study on the willingness to pay to avoid power outages. Energy Econ., 30: 1232-1245.

Cerullo, V. and M.J. Cerullo, 2004, Business continuity planning: a comprehensive approach. Inform. Syst. Manag., $\quad 21$ : 70-78. DOI: 10.1201/1078/44432.21.3.20040601/82480.11

Emerson Network power, 2008. Small Businesses Are Unprepared for Power Outages: Next Blackout Could Put Them in the Red. Viconics Electronics Inc. http://www.pr-inside.com/print754076.htm
Eto, J., J.G. Koomey, B. Lehman, N. Martin and E. Mills et al., 2001. Scoping study on trends in the economic value of electricity reliability to the U.S. economy. Formal Report, Macmillan Encyclopedia of Energy. http://ies.lbl.gov/node/238

Green, P.E. and V. Srinivasan, 1978. Conjoint analysis in consumer research: issues and outlook. J. Consumer Res., 5: 103-123.

Green, P.E. and V. Srinivasan, 1990. Conjoint analysis in marketing: new developments with implications for research and practice. J. Mark., 54: 3-19. DOI: $10.2307 / 1251756$

Hilsenrath, J.E., 2003. The 2003 blackout: Economy won't likely be derailed; cost could hit 6 billion. Wall Street J., https://wpweb2.tepper.cmu.edu/ceic/pdfs/CEIC_05 -06.pdf

KPMG, 2002. Business Continuity Study: Benchmark Report A review of the factors influencing Business Continuity in the next millennium. Benchmark Report. Contingency Planning and Management. http://www.auditnet.org/docs/BCP/Business Continuity Report Benchmark Study.pdf

LaCommare, H.K. and J.H. Eto, 2006. Cost of power interruptions to electricity consumers in the United States (US). Energy, 31: 1845-1855. DOI: 10.1016/j.energy.2006.02.008

Loeffler, C., 2008. 10 Ways to Save Energy in Your Data centre, Foresight: Buildings, 5: 64-68.

Louviere, J.J., D.A. Hensher and J.D. Swait, 2000. Stated Choice Methods, Analysis and Application. 1st Edn., Cambridge University Press, Cambridge, ISBN-10: 9780521788304, pp: 418.

Momani, N.M., 2010. Business continuity planning: are we prepared for future disasters. Am. J. Econ. Bus. Admin., $\quad 2$ 2: 272-279. $\quad$ DOI: 10.3844/ajebasp.2010.272.279

Paddon, D., 2004. Most businesses still unprepared for a major blackout, disaster, studies find", Canadian Press. The Canadian Press. http://www.fusepoint.com/english/news/in_the_ne ws/Most\%20businesses\%20still\%20unprepared.pd f.pdf

Rodentis, S., 1999. Can your business survive the unexpected? J. Accountancy. http://www.questia.com/googleScholar.qst?docId= 5001233723

Savage, M., 2002. Business continuity planning. Work Study, 51: 254-261. DOI: 10.1108/00438020210437277 
Webb, G.R., K.J. Tuierney and J.M. Dahlhamer. 2000. Business and disasters: empirical patterns and unanswered questions. Natural Hazards Rev., 1: 83-90. DOI: 10.1061/(ASCE)1527-6988(2000)1:2(83)
Zolkos, R., 1997. Property Loss Control: 'Just-in-Time’ Approach Exacerbates Risk of Contingent Business Interruption. Business Insurance. http://www.businessinsurance.com/article/1997081 7/ISSUE01/10008993 